\title{
MEMORANDA
}

\section{Louis Pasteur: una vida, una ciencia, un siglo}

\author{
Carlos E. Sánchez
}

\begin{abstract}
"Las artes y las ciencias no se funden en un molde sino que se forman y perfeccionan por grados, con el uso y pulido frecuente, como los osos lamen perezosamente a sus cachorros para darles forma".
\end{abstract}

Michel Eyquem Montaigne

Louis Pasteur, el "benefactor de la humanidad", vivió durante una época llena de cambios, adelantos, guerras y planteamientos filosóficos y políticos que revolucionaron totalmente a la sociedad del siglo XIX.

Pasteur nació en Dole el viernes 27 de diciembre de 1822, a las dos de la mañana, en el seno de una familia modesta que nunca había tenido importancia. Los Pasteur fueron originarios de una pequeña población de Haut-Doubs situada en la región más fría de Francia donde la vida era bastante ruda. El apellido de la familia indicaba, por lo demás, que los ancestros del sabio estaban relacionados con el pastoreo. Criado bajo la admiración bonopartista desde que aprendió el alfabeto, el niño que se convertiría en el sabio más celebre de Francia decía frecuentemente a su padre: "Al enseñarme a leer, tú tenías la intención de hacerme conocer la grandeza de Francia". Un padre parco en palabras, pobre en bienes y una madre sumisa dedicada por entero al cuidado de las tres hijas fueron el centro del ambiente austero que acompañó durante la infancia y la adolescencia de Pasteur.

Años más tarde, en 1883, con motivo de la inauguración de una placa conmemorativa, Pasteur se refirió orgullosamente a sus años de niñez: "Tu entusiasmo, querida madre, me lo trasmitiste. Si siempre he asociado la grandeza de la

M.D, Docente, Escuela Colombiana de Medicina. ciencia con la grandeza de la patria fue porque fuí impregnado de los sentimientos que me inspiraste. $Y$ tú, querido padre, en quien la vida se comportó tan rudamente como tu trabajo, me enseñaste lo que puede lograr la paciencia durante los largos trayectos de la existencia. Es a tí a quien debo la tenacidad en el trabajo cotidiano. Tú tuviste no solamente la perseverancia que hace de la vida algo útil, sino también la admiración por los grandes hombres y los grandes hechos".

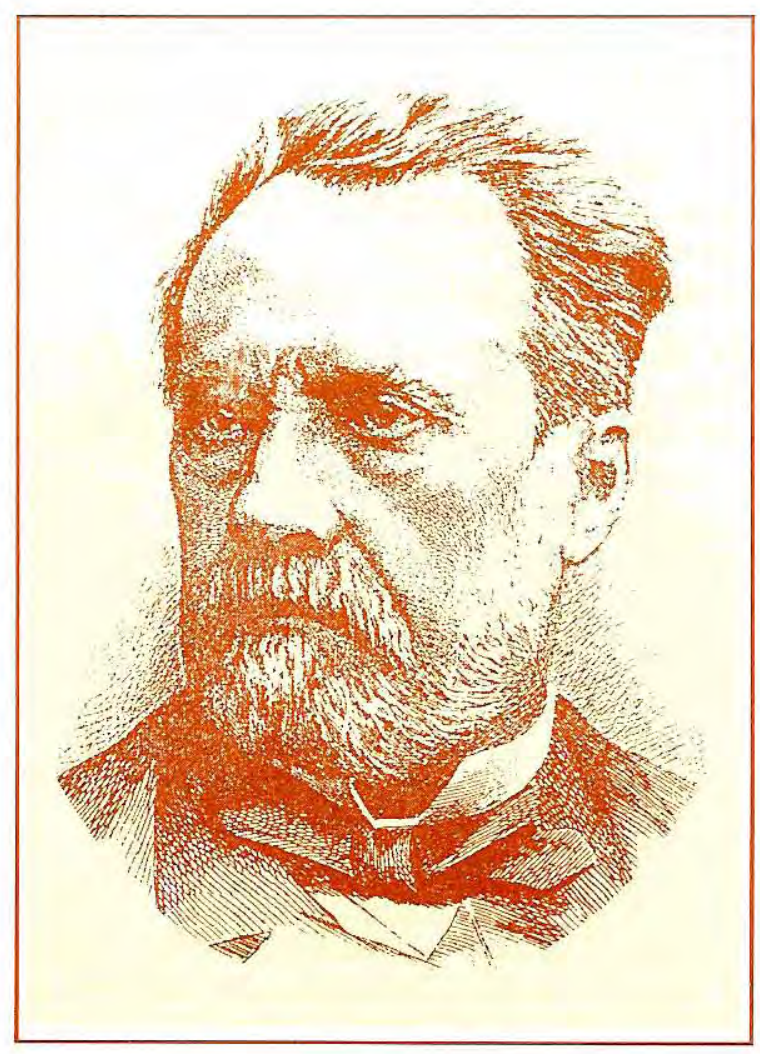

Louis Pasteur, 1822-1895. 
Pasteur nació un año después de la muerte de Napoleón Bonaparte, el emperador que compartió con sus conciudadanos el entusiasmo por todo lo antiguo y con especial preferencia por lo romano. Y, así como los batallones franceses tomaron las águilas de las antiguas legiones romanas como insignia, así mismo el simple ciudadano introspectó la magnificencia de un imperio. Napoleón impuso orden a lo que había sido caos político y consolidó el pensamiento y la fe en un pueblo que durante años había sufrido por su desorientación sociopolítica.

El sentido por el orden se proyectó en las artes. El vocero artístico más coherente del mundo severo del fervor revolucionario sería Santiago Luis David, un pintor cuyo temperamento y técnica se adaptaron de manera ideal al espíritu de la época. Innovador por naturaleza y entusiasta de lo clásico por su formación, David pintó cuadros cuya austeridad era una reacción consciente a las extravagancias del rococó. Burgués por nacimiento y crianza, David dirigió con franqueza y valor su arte al recién establecido orden de la clase media. Por ello, asumió el papel de un político poderoso en el campo del arte, con efecto de enorme trascendencia. Más académico que sus predecesores academistas, sentó con éxito las bases del arte oficial que perdurarían durante todo el siglo XIX.

Su discípulo, Juan Augusto Domingo Ingres, quien fuera también senador de la república, continuó con el orden establecido en la pintura advirtiéndose en sus figuras la calidad de las líneas puras y límpidas. A semejanza de su maestro, aceptó el credo estético del arte como representación de la naturaleza, con la connotación de que era tarea del artista dar orden al proceso de redisposición y síntesis.

En el campo musical La tercera sinfonía de Ludwing van Beethoven, que el mismo compositor intituló Heroica, fue ejecutada por primera vez en París en 1828, veinticinco años después de la fecha en que fue compuesta. Romain Rolland, el escritor francés de la época ulterior declaró, con todo el balance de la historia a su favor que: "La Heroica es un Auterlitz de la música, la conquista de un imperio; y el de Beethoven ha perdurado más que el de Napoleón". En las composiciones instrumentales del músico, los ideales de libertad, igualdad y fraternidad, alcanzaron su expresión más abstracta y universal en su forma más pura. Beethoven usó el enorme poder de su arte para expresar la esencia de estos grandes objetivos humanos y al hacerlo iluminó el camino del hombre en su lucha por alcanzar su destino último de progreso y perfección. En su obra reflejó la lucha titánica entre las actitudes antagónicas de sumisión y afirmación, entre la pasividad y la actividad y entre la aceptación y el desafío.

Mucho antes de la romántica revolución de julio de 1830 , bullían nuevas ideas en la mente y la imaginación de los intelectuales y artistas franceses. En 1827, Víctor Hugo publicó su Cromwell, el drama que serviría de proclama del romanticismo. Guizot daba conferencias en La Sorbona sobre la historia de Francia y Eugenio Delacroix con su cuadro La libertad guiando al pueblo daba a esos gloriosos días su expresión incandescente.

Más elocuente que cualquier escrito de historia, el lienzo subyugć los sentimientos de aquellos que aún permanecían impávidos ante los cambios de una sociedad ávida de reformas. Es explicable entonces por qué la arquitectura, la música y la literatura se asociaron con el resurgimiento patriótico y nacionalista encauzando las energías hacia nuevos vuelos de la imaginación, dando al espíritu francés una puerta de escape a los recientes sueños de gloria imperial romana, que habían terminado en la pesadilla de la derrota napoleónica.

La Sinfonía fantástica de Berlioz, estrenada en 1830 , contenía un extracto de muchas ideas de la atmósfera musical y literaria del ambiente de la época. La forma musical inscrita en la tradición sinfónica beethoviana tiene como característica en la técnica el empleo de la idea fija con la cual el compositor expresaba la idea de su amada, presente en todas partes y que se adueña de todos sus pensamientos. El dolor, el horror y el amor se escuchan a través de toda la riqueza instrumental y el empleo al máximo del color sonoro. En su gigantesto Requiem se empleó una inmensa orquesta de base, un coro de 500 voces, un tenor solista y cuatro enormes 
bandas militares con el objeto de reforzar el efecto acústico cuando suenan las trompetas en el día del juicio final. Como un Napoleón musical, Berlioz fue el primero de los directores de gran orquesta y el prototipo de los grandes maes tros de nuestros días.

La dinámica del periodo revolucionario, con sus cataclismos políticos, sociales e industriales, enfrentó a los franceses a la imagen de un mundo de rápidos cambios. El desplazamiento de la responsabilidad y la riqueza de las manos de la aristocracia a la clase media trajo un cambio absolutamente asombroso. Las artes dejaron de ser producidas sólo para un pequeño grupo elitista de aristócratas, en vez de ello fueron dirigidos a un público anónimo cada vez mayor, principalmente de la clase burguesa.

En lo político, la revolución estallaba en París en 1848 para extenderse espontáneamente por toda Europa. A pesar de que los levantamientos fueron dominados, pocos observadores predijeron que 1848 había sido el año de la última gran revolución general en Europa. Pero, si la clase política le prestó atención a las barricadas de París y Viena, poco se fijaron en lo que estaba sucediendo en las calles de las ciudades industriales como Manchester y Bradford, en los centros fabriles como Lieja o Lille donde se gestaba otro tipo de revolución, que en los veinticinco años posteriores a la derrota de las revoluciones políticas de 1848 transformaría permanentemente la economía y la sociedad de Europa occidental y, antes de finalizar el siglo, de gran parte del resto del mundo, incluyendo a Estados Unidos.

La transformación social durante y posterior a la industrialización, cambió radicalmente el curso de la historia y abrió insospechadas perspectivas y posibilidades para la vida del hombre. Basta enumerar sólo algunas de sus consecuencias: el crecimiento de la población, la emigración del campo a los centros urbanos, el desarrollo de las ciudades, el nacimiento de la economía industrial y del capitalismo y la aparición del germen del proletariado.

En ningún otro periodo histórico, el crecimiento económico ha causado mayor impacto en los hombres que lo presenciaron entre 1848 y 1873. La industrialización tuvo un efecto profundo en la tradición humanística y científica. En 1789, la Asamblea Nacional Francesa había proclamado "los derechos naturales e inalienables del hombre y del ciudadano". "Los hombres", declaraba, "nacen libres y continúan siendo libres e iguales en sus derechos" definidos como la libertad, la propiedad privada, la inviolabilidad de la persona y la resistencia contra la opresión. En el curso del siglo XIX se establecieron en el mundo occidental instituciones políticas representativas, derechos individuales y políticos, igualdad ante la ley, libertad de opinión y de prensa y libertad de conciencia y de asociación.

Los empresarios vieron cómo la ciencia que constituía el modelo sobre el que se establecían las leyes de la economía, confirmaba su rol en la remodelación del mundo. La ciencia remplazaba la filosofía y desafiaba la religión, al tiempo que proporcionaba seguridad gnoseológica y permitía el dominio sobre la naturaleza, clave del desarrollo tecnológico.

La demostración de la superioridad de los métodos de las ciencias físicas y naturales fue la tarea intelectual del positivismo de Auguste Comte quien elaboraría su famoso paradigma de los tres estados en el progreso del conocimiento humano: el tecnológico, el metafísico y el científico. La publicación en 1859 de El origen de las especies de Charles Darwin fue un paso decisivo en la abolición de la línea divisoria entre las ciencias naturales y el estudio del hombre. La autoridad de Darwin la invocaron tanto Marx como T. H. Huxley en apoyo de la agresiva ideología secular, habiendo sido utilizada posteriormente para justificar una concepción competitiva de la historia y la superioridad social de la raza blanca.

El hombre es producto de su entorno y su historia. A Louis Pasteur le tocó vivir durante un periodo de permanente cambio con un pasado glorioso rico en belleza y majestuosidad. Un periodo donde hubo un emperador, una ocupación extranjera, una restauración, dos reyes, una nueva monarquía - aunque burguesa, una segunda república, un segundo imperio - a veces dictatorial, a veces liberal pero siempre 
fastuoso e imponente, una segunda ocupación extranjera, una guerra civil, la Tercera República, en fin, una estructura dudosa en la cual los monarquistas, bonapartistas, socialistas y republicanos se mezclaron en luchas filosóficas y políticas. En las minas y las fábricas, la revolución industrial renovó la faz de la tierra que vió atravesados sus campos por el ferrocarril, los mares por los barcos a vapor y sus cielos por la electricidad. La explotación del hombre por el hombre, aunque no nació en ese siglo, tomó proporciones iguales a las del capitalismo mundial. Sin embargo, jamás las ciencias progresaron tanto. Institutos, laboratorios, bibliotecas se inauguraron por doquier. Las revistas se convirtieron en el mejor apoyo del investigador quien pudo reunirse con sus pares en congresos, en sociedades, en academias. Todas las disciplinas evolucionaron: la arqueología, la geología, la termodinámica, la filología y la fisiología. El laboratorio se compenetró con la industria creando nuevos colorantes, nuevas medicinas y nuevas técnicas.

Fue un siglo que se inició con los ejércitos napoleónicos avanzando a pie como aquéllos de Julio César, pero, los de Bismark lo hicieron en tren orientados por el telégrafo. Cuando comienza el siglo el hombre utiliza su propia fuerza o la del animal y cuando termina tiene a su disposición una fuerza mecánica 10 o 20 veces superior a la de un caballo. Cuando debuta sola la conciencia con la razón, resiste a las pasiones; cuando finaliza, el inconsciente toma su lugar.

Artistas, filósofos, médicos, ideólogos, escritores, químicos y físicos apenas tuvieron tiempo para percatarse que estaban en una especie de marmita mágica donde se entremezclaron todas las inquietudes para inventar un mundo moderno.

Allí estuvo Louis Pasteur como protagonista de esa época en donde las barricadas, los campos de batalla y los barrios pobres fueron caldo de cultivo para el cólera, la peste misma, el tifo, la tuberculosis y la difteria, que encontraban un ambiente propicio para su propagación. Allí estuvo para ponerle freno a la infección y a la muerte.
Luis Pasteur (1822-1895) es, sin duda, uno de los científicos más populares. Todo el mundo convive con el resultado de sus trabajos: la pasteurización de los lácteos, la calidad de las cervezas y vinos y la prevención de las enfermedades virales. Muchos conocen los resultados de sus estudios acerca de la generación espontánea y sobre todo su descubrimiento de la vacuna contra la rabia. Descubrimiento que lo coloca en el Olimpo de la medicina y que, aún en vida, le ganara el título de "benefactor de la humanidad".

Pasteur no fue médico, ni veterinario. El acerbo intelectual e investigativo de normalista hizo de él un químico, especialista en una disciplina como la cristalografía, fuente y ayuda para múltiples investigaciones de los científicos franceses. Nada lo preparó para orientarse hacia la medicina; nada preveía que dejara el cristal por el hospital. Fue dentro de él que germinó la fuerza que lo conduciría desde la asimetría molecular al microbio y a la lucha contra las enfermedades infecciosas. Sus trabajos característicamente variados gozaron de la particularidad de haber tenido inmediatamente gran cantidad de aplicaciones, médicas por supuesto, pero también agroindustriales.

En todos estos campos se evidenció una importancia social y económica considerable. Pocas veces un hombre de ciencia ha sido el origen de una cascada de cambios y reformas en campos tan distintos: la salud individual y la higiene pública, la agricultura y la industria. Escasas han sido las ocasiones donde la investigación científica tuviese resultados inmediatamente tangibles para la sociedad y, aún más, que fuesen benéficos y reconocidos por todos. Pasteur, incluso, tuvo la fortuna de ser apoyado por los poderes públicos para obtener el financiamiento económico para sus investigaciones y motivar a los industriales y agricultores para que emprendiesen ellos mismos los derroteros del progreso tecnológico.

A todo esto Pasteur debió su popularidad. Rápidamente fue considerado el arquetipo de sabio, aliado de la ciencia y la beneficencia, la bondad y el desinterés. Esta reputación fue amplificada 
por sus amigos y notablemente por su yerno René Vallery Radot, autor de la Vida de Pasteur, obra de consulta durante muchos decenios. En el curso de medio siglo Pasteur fue "San Pasteur". Pero, los tiempos han cambiado. La sociedad evolucionó y esta imagen mitificada algo legendaria ya no es la misma. Pasteur hoy nos parece haber sido un excelente representante de la burguesía del siglo XIX, defensor del orden social y moral, no solamente por gusto y convicción sino porque era indispensable para el desarrollo económico.

Fue un conformista absoluto en lo moral y lo religioso. Partidario del poder fuerte y siempre al lado del poder. Los testimonios apoyan esta imagen: tenía un carácter violento y a veces despectivo. Sólo vivía para su trabajo para el cual era muy paciente, cuidadoso y obsesivo. Pocas fueron sus distracciones; leía poco, aunque apreciaba la poesía de Francoise Coppée (contemporáneos fueron Baudelaire, Rimbaud y Verlaine) y pintaba cuadros que pocos conocieron, pero disfrutaba de los honores y las adulaciones. Durante el tiempo que fue administrador de la Escuela Normal Superior no dejó un grato recuerdo por su excesivo autoritarismo. No se trata de hacer un juicio a Pasteur, sólo nos empuja el deseo de concebirlo como un ser humano, como un hombre ávido por el orden, en todo el sentido del término, incluso en los excesos. Fue la clave del éxito de sus trabajos que consistieron siempre en la búsqueda de un orden de las cosas; partiendo de situaciones confusas, el genio de Pasteur permitió la obtención del orden a través de una metodología fundamentada en la constancia, la paciencia y la aplicación.

Todas sus investigaciones fueron sistemáticamente precedidas del estudio de los antecedentes históricos que ordenaba meticulosamente. Unicamente después de esta labor procedía Pasteur a un acercamiento experimental, no muy original es cierto, pero siempre ejecutado y concebido de mejor manera que la de sus antecesores. La postura de orden en las observaciones o experimentos era muy difícil puesto que, a diferencia de hoy, no se disponía sino de un cuadro teórico muy rudimentario.
El principio de orden no sólo se encuentra en el método pasteuriano sino también en la naturaleza de los trabajos. Estos aparentemente muy diferentes, siempre tuvieron origen en las posibles aplicaciones prácticas, en las asignaciones tanto industriales como de las áreas públicas. Su primer trabajo fue aquél de un químico puesto que centró su atención en la capacidad rotatoria de las soluciones de ácido tartárico sobre el plano de polarización de la luz. Estando aún muy lejos del conçpto microbiológico, percibió que de los dos isómeros ópticos del ácido, uno sólo es producido por los seres vivos y que uno sólo (el mismo) es susceptible a la fermentación. La conclusión de Pasteur fue novedosa, en vez de ser una descomposición de la materia orgánica como lo pretendía Justus von Liebig (su adversario), está ligada a la vida y con mayor precisión a la acción de ciertos microorganismos.

De la misma manera, el estudio de la fermentación fue consecuente y lógicamente continuados con los trabajos sobre la disimetría molecular. La solicitud concreta de un fabricante de alcohol que tenía dificultades con la fermentación del jugo de remolacha permitió demostrar que no solamente las fermentaciones son inherentes a la vida sino que existen diferentes clases, cada una debida a un microorganismo en particular (la levadura de la cerveza causa la fermentación alcohólica, la levadura láctica, la fermentación láctica, etc.). Por ello, Pasteur comenzó a estudiar los diferentes productos de las fermentaciones.

El estudio de la generación espontánea se articuló sobre un doble interrogante: ¿de dónde provienen los microorganismos responsables de las fermentaciones? ¿Cómo unir el origen de la vida con el origen de la disemetría molecular característica de los seres vivos? A esto se agregó la publicación del libro L'heterogenie ou traité de la generation spontanée, en 1859, en el cual Felix Archimede Pouchet se declaraba partidario de la generación espontánea con argumentos científicos y filosóficos totalmente opuestos a los de Pasteur.

La aparición de esta obra sirvió de acicate al genio francés para demostrar la inexistencia de 
la generación espontánea y para resolver el problema del fabricante de alcohol: las cubas de su empresa estaban contaminadas por microorganismos que interferían con la fermentación productiva de alcohol. La aplicación práctica del estudio fue la instauración de métodos higiénicos para la industria del vino, la cerveza y el vinagre y la pasteurización de estos productos. Económicamente fue benéfico para él, pues, las exportaciones del vino aumentaron al poder garantizar la calidad del líquido.

Pero, ¿cómo se convirtió Pasteur en el revolucionario de la medicina? Dos eventos de su carrera parecen decisivos para aportar una respuesta a la pregunta. El primero fue la epidemia de cólera en 1865. Como miembro de una comisión científica consultora, Pasteur abandonó la atmósfera confinada de su laboratorio para descubrir con repugnancia el infierno cotidiano de las salas del hospital Lariboisiere donde se apretujaban los pacientes. Estaba persuadido de la existencia de un agente responsable de la enfermedad y ensaya encontrarlo en los conductos de la calefacción, o cerca de los lechos de los enfermos que fallecen de enteritis; sin llegar a descubrirlo como lo haría Kock en Egipto en 1883.

No obstante fueron las enfermedades del gusano de seda las verdaderas causantes de que el químico francés se encauzara hacia la vía biomédica. En verdad, Pasteur no tenía ningún interés por el gusano, su metamorfosis, ni por las enfermedades destructoras del metazoario, pero ante una solicitud de Jean Baptiste Dumas y de Napoleón III, el rechazarla hubiera sido indigno y fatal para la industria nacional. Sin embargo, algo era atrayente: el poder hacer investigación fundamental y tener la posibilidad de aplicar los resultados en hechos concretos.

La coherencia de la obra pasteuriana estuvo asegurada por el microbio. La infección de las crisálidas del gusano de seda junto con la fermentación del jugo de la uva, la aparición del pus y el ciclo del carbunco le facilitaron el entendimiento integral de la biología. De la química a la inmunidad, de una etapa a la otra, no hubo rupturas aparentes.
No es al azar que Pasteur se inclinara hacia la patología infecciosa. Dentro de los múltiples campos de investigación abiertos por el concepto biológico, introducido años antes por Lamarck, Pasteur designó claramente la investigación médica como resultado de las ciencias de la vida. El abandono sucesivo del cristal y después del fermento, revelaron en definitiva la jerarquía de las preocupaciones del químico francés.

Pero, la revolución biomédica no fue fácilmente aceptada. Pasteur debió luchar contra sus pares e imponerse ante los médicos. Muchos pensaban que un médico no necesita ser un sabio, sino un practicante, antes que todo.

Una vez introducido en el estudio de las fermentaciones, Pasteur hizo del microbio su caballito de batalla y del microscopio su arma predilecta. Basta imaginarse el asombro de los cirujanos que lo rodeaban cuando dibujaba en el tablero las cadenas de estreptococos causantes de las infecciones puerperales, no obstante que, después del siglo XVII cuando Leuwenhoeck describiera los "bichitos maravillosos" que observaba con el microscopio, éstos ya no eran una novedad. ¿Por qué entonces tanta reticencia de los médicos del siglo XIX? La aplicación estaba en la actitud de Pasteur que no se contentó con observar, sino que afirmó el papel deletéreo de estos seres y su poder patogénico lo que conmocionaba el saber médico al describir el mundo lleno de peligro y amenazado por enemigos invisibles. Exigió un replanteamiento de las relaciones entre medicina y ciencia, entre el mundo de la investigación y aquél de la asistencia.

Pasteur no creó solamente la biología médica, sino que introdujo un nuevo control y consecuentemente un nuevo poder: ninguna práctica médica se debía resistir a una experimentación rigurosa; el médico no debía perder de vista que su acción se continúa en el mesón del laboratorio. Allí es donde se declaró la guerra contra el microbio que se domesticó con ayuda de los caldos de cultivo. La revolución pasteuriana asoció internamente la teoría con la práctica. 
El estilo apasionado de las intervenciones de Pasteur en la Academia de Ciencias, sus palabras altaneras y a veces despreciativas, demuestran bien cuántas rivalidades, cuántas frustraciones tuvo que enfrentar. Al final de estas justas oratorias por algunos aplausos aprobatorios tuvo que tolerar muchos silbidos y zapateos como demostración de rechazo.

Frente al cristalógrafo de la calle de Ulm, el cuerpo médico se aglomera en bloque y se cubre con la legitimidad con actitudes semejantes a las de Diafoirus o Purgon de Molière: hablaban mucho de arte, pero, poco de ciencia. Además, porque eran responsables de la suerte de los enfermos, ciertos médicos se imaginaban a veces, ser propietarios de las enfermedades. No apreciaban en ningún momento que un sabio, no médico, les viniera a dar lecciones de humildad o les invitara a la meditación.

Lógicamente, Pasteur no fue el único en chocar con esta hostilidad. Antes que él, Claude Bernard, que sí era médico, se expuso a las burlas de algunos de sus colegas al abandonar el bisturí y la tijera por los animales de experimentación. A pesar de que renovara el saber fisiológico y la teoría de la medicina experimental, se encontró bajo la incomprensión que envolvió sus investigaciones por lo que amargamente declaró en la sesión inaugural del Colegio de Francia: "La medicina científica que tengo por misión enseñarles, no existe".

¿Es diferente la situación actual? Estudiantes y profesores de las facultades de medicina con frecuencia se ignoran. Se comienza por las ciencias básicas para estar seguros de haberlas olvidado en el momento de la especialización.

Por ello, la actitud de Pasteur fue ejemplar al insistir en los lazos de unión indispensables entre el enfermo y el laboratorio del investigador. Desde la disimetría molecular a la biología, de la bacteria a la inmunología, del laboratorio al hospital, el recorrido de Pasteur permitió comprender lo que debe ser la investigación e incitó a reflexionar sobre el papel del investigador en el equipo médico. Vista externamente, esta cooperación entre médicos e investigadores parece ser material, pero, en realidad, existe una pro- funda y antigua resistencia en el acercamiento del sufrimiento humano del enfermo con la visión exclusivamente científica del investigador. De allí, que fueron necesarios varios decenios para comprender a cabalidad la lección pasteuriana.

Aun más, cuando la sociedad juzga al médico más por su eficacia en curar que por su capacidad de estudiar la enfermedad. Que el hospital universitario sea un lugar de observación y reflexión científica, éticamente controlada, ha perdido importancia por parte de administradores y gerentes que desean ver aumentada la asistencia. De una y otra parte, se plantea una merma de la libertad; aquélla de los investigadores que critican al cuerpo médico en su conocimiento, discutiendo con él, en ocasiones, la legitimidad científica y la de los practicantes y administradores que reprochan a los sabios el no ser capaces de escuchar las quejas de los enfermos ni los gritos de los moribundos. Para evitar el diálogo de sordos, es necesario renovar continuamente los contactos por lo que el ejemplo de Pasteur adquiere más actualidad.

En los tiempos del SIDA, el investigador no debe esperar que sea el médico el que le designe el campo de sus búsquedas. Esta enfermedad conduce hacia las fronteras de la microbiología y la inmunología. Extrañas y profundas similitudes surgen entre los problemas específicos de esta afección y aquéllos que fuesen las preocupaciones de Pasteur. ¿No fue capaz de tratar preventivamente la rabia, sin haber visto jamás el virus, contentándose en presentir su presencia en el cerebro de los perros enfermos?

Pasteur creó las bases de la inmunología al demostrar que un virus puede mutar atenuándose para convertirse en vacuna y que de este virus-vacuna proviene la enfermedad al alterar el medio propicio a la virulencia gracias al estímulo del sistema inmunitario. Hoy, el virus del SIDA nos enfrenta con un proceso inverso: estamos ante un virus que muta para ganar en virulencia y que ataca directamente el sistema inmunológico poniéndose al abrigo de los anticuerpos neutralizantes.

Rabia y SIDA, una misma lucha. Es cierto que Pasteur buscó aprovechar la prolongada incu- 